\title{
Management of Acute Coronary Syndrome in Patients with Chronic Kidney Disease: If We Don't Risk Anything, We Risk Even More
}

\author{
Muhammad Asim $^{a}$ Robin Fraser Jeffrey ${ }^{b}$

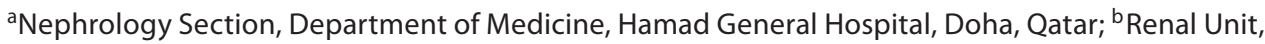 \\ Bradford Teaching Hospitals NHS Foundation Trust, Bradford, UK
}

\section{Key Words}

Acute coronary syndrome $\cdot$ Acute kidney injury $\cdot$ Chronic kidney disease $\cdot$ Contrast-induced nephropathy

\begin{abstract}
The utilization of coronary angiography and percutaneous coronary intervention in the routine care for patients with acute coronary syndromes (ACS) has resulted in significant improvement in their prognosis. Consequently, recommendations on the use of these management strategies are reflected in the ACC/AHA guidelines for the management of patients with unstable angina and myocardial infarction. However, among other causes, the 'phobia' of nephrotoxicity of iodinated contrast media (ICM) in chronic kidney disease (CKD) patients and its claimed adverse effect on shortterm and long-term survival has led to a worryingly low use of ICM-based diagnostic and therapeutic interventions in patients with CKD. We argue that the fear of iodinated contrast media-induced acute kidney injury (ICl-AKI) is not a valid reason to avoid ICM-based investigations/interventions in CKD patients with ACS; the risks of myocardial infarction and death greatly outweigh the risk of ICI-AKI in most of these patients and hence they should always be considered for myocardial revascularization.
\end{abstract}

Copyright $\odot 2011$ S. Karger AG, Base
(C) 2011 S. Karger AG, Basel

$1660-2110 / 11 / 1194-0333 \$ 38.00 / 0$

Fax +4161306 1234 E-Mail karger@karger.ch www.karger.com
Accessible online at:

www.karger.com/nec

\section{Introduction}

Patients with acute coronary syndromes (ACS) carry a poor prognosis. The Euro Heart Survey of Acute Coronary Syndromes global registry data indicate that the 30 -day mortality rate ranges from approximately $2 \%$ for patients with unstable angina to $7 \%$ for patients with non-ST elevation myocardial infarction (NSTEMI) and $11 \%$ for those with ST elevation myocardial infarction (STEMI) [1]. Similarly, data from the Family Heart Study indicate that $25 \%$ of men and $38 \%$ of women will die within a year of having an initial, recognized myocardial infarction (MI). Another 18\% of men and 35\% of women will have a second MI within 6 years; myocardial damage will lead to cardiac failure in approximately $22 \%$ of men and $46 \%$ of women during this time [2].

In light of the growing risk markers and aging population, ischemic heart disease is likely to remain the leading cause of morbidity and mortality in the foreseeable future and thus poses a key health challenge worldwide.

\section{Guidelines for Treatment of ACS in the General Population}

Current treatment guidelines for patients with ACS include early coronary intervention. The 2007 STEMI focused update of the ACC/AHA 2004 guidelines recom- 
mend primary percutaneous coronary intervention (PCI) within 90 min of medical contact in STEMI patients presenting to hospitals with a PCI facility (Class 1, level of evidence A) [3]. Coronary angiography with intent to perform PCI (or CABG) is also recommended for STEMI patients treated with fibrinolytic agents who have cardiogenic shock, congestive heart failure, electrical instability or persistent ischemic symptoms [3]. Similarly, The 2007 ACC/AHA guidelines have given the early invasive strategy a class 1 , level of evidence A recommendation for patients with UA/NSTEMI and high-risk features [4]. The goal is to minimize ischemia time by timely reperfusion, as this translates into important reductions in morbidity and mortality.

\section{Poor Compliance with Treatment Guidelines in ACS Patients with Coexisting Chronic Kidney Disease}

There is evidence that in the stratum of patients with chronic kidney disease (CKD), standard guidelines are not adhered to with respect to cardiac catheterization and PCI following ACS [5-7]. This is alarming because epidemiologic and natural history studies have confirmed that CKD is a prevalent, independent risk factor for all-cause and cardiovascular mortality. Hence, it is plausible that CKD patients would derive greater absolute benefits from an interventional strategy than patients without CKD.

The main barriers to implementing the ACC/AHA guidelines for the management of CKD patients with ACS include lack of prospective clinical trial data, atypical clinical presentation of ACS (lower peak of CK-MB concentration, less common ST segment elevation), under-recognition of a patient's poor prognosis and underestimation of therapy benefit. In addition, the 'phobia' of iodinated contrast media-induced acute kidney injury (ICI-AKI) has continued to haunt the medical community for more than a decade, leading to under-use of coronary angiogram/PCI in these patients $[5,8]$.

\section{Assessing the Risk-Benefit Ratio in CKD Patients Presenting with ACS}

Risk is computed as the product of probability of the hazard and its potential impact, i.e. risk $=$ (likelihood of event occurring) $\times$ (impact of event occurring). Iodinated contrast media (ICM)-enhanced imaging is associated with risks that must be considered relative to the benefits of obtaining the imaging information. In the next sections, we will analyze the risks (in the context of ICI-AKI) and benefits of an ICM-based diagnostic/interventional study in a CKD patient with ACS.

\section{Risk of Developing ICI-AKI Is Relative; ICI-AKI Is Usually Mild and Reversible}

ICI-AKI is a term used to describe AKI secondary to intravascular administration of ICM [9]. The concept of ICI-AKI was substantiated by several earlier studies demonstrating an increased risk of AKI following cardiac procedures in CKD patients. It stimulated a lot of research interest because of its apparent adverse effect on short-term and long-term survival in affected patients. However, this clinical entity has also received its share of criticism with regards to its existence, as well as to its claimed cause-effect relationship with morbidity and mortality. Newhouse et al. [10] pointed out in their study that an increase in serum creatinine was observed as frequently in hospitalized patients who did not receive ICM as it was in reported series of patients who received ICM. Consequently the incidence of ICI-AKI might have been overestimated in previously published studies on ICI-AKI due to lack of a control group that did not receive ICM [10]. The diagnosis of ICI-AKI requires exclusion of other known causes of AKI, and at times it can be difficult to disentangle the effect of ICM from that of other coexisting risk factors, which leaves us uncertain about the etiology of AKI. Furthermore, the cause-effect relationship between ICI-AKI and adverse outcomes has not been established either. Development of ICI-AKI might just have identified a highrisk group of patients that would have fared poorly anyway.

The risk of developing ICI-AKI is relative, not absolute. Indeed, with the use of prevention strategies, the risk of clinically relevant ICI-AKI is quite low in most situations; the risk of severe ICI-AKI requiring dialysis after coronary angiography/PCI is even rare [11]. A recent study showed that coronary angiography and/or PCI (compared to medical treatment) did not cause further compromise of renal function at 6 months of follow-up in CKD patients with ACS [7]. Another retrospective analysis of 482 patients undergoing pretransplant screening coronary angiograms did not reveal any acceleration in the rate of decrease in renal function in these patients who had severe renal impairment [12]. Moreover, patients who develop ICI-AKI show only a mild rise in serum creatinine that returns to the baseline within 7-14 days, with no permanent sequelae. Hence, there is no justification 
for attempting to predict wider negative impacts of ICM study.

\section{Coronary Artery Disease Is Common, Severe and} Associated with Worst Outcomes in CKD

Whether or not ICI-AKI exists, frequent development of coronary artery disease in CKD patients is a hard fact. Approximately $40 \%$ of patients who present with ACS have some degree of renal dysfunction [13]. Even a mildto-moderate degree of CKD constitutes an independent risk factor for the development of coronary artery disease $[14,15]$, which tends to be far more severe due to the comorbid effects of diabetes mellitus and obesity, higher rates of vascular calcification, and a variety of nontraditional risk factors [16]. Furthermore, evidence is mounting that in patients with CKD (including those with mild CKD) cardiovascular morbidity and mortality is increased after ACS $[6,17,18]$. The relationship is linear and inverse such that mortality increases as glomerular filtration decreases [19]. Shlipak et al. [16] in their analysis of 130,099 elderly patients hospitalized with MI observed that 1 -year mortality was $24 \%$ in patients with no renal insufficiency, $46 \%$ in patients with mild renal insufficiency and $66 \%$ in patients with moderate renal insufficiency. A similar trend was noted in two major trials of 18,000 patients with acute STEMI: GUSTO IIb and III [20].

It is noteworthy that most CKD patients die a cardiovascular death before progressing to the stage of requiring renal replacement therapy. Keith et al. [21] followedup approximately 28,000 patients with $\mathrm{CKD}$, and observed that only $3 \%$ of patients with stage II-IV disease progressed to renal replacement therapy, while 25\% died over the 5-year observation period. Even among those with advanced stage IV disease, death prior to renal replacement therapy was more than twice as likely as progression to end-stage renal disease.

Intervention in ACS Saves Lives and Decreases Future Cardiovascular Events

The FRISC II trial showed that an early invasive treatment strategy reduced mortality and the occurrence of MI in patients with unstable coronary artery disease [22]. The TACTICS-TIMI 18 trial was the first study to show in a randomized manner that the beneficial effects of such treatment were maintained in patients with CKD [15]. Johnston et al. [19] performed a subgroup analysis of patients in the FRISC II trial who had CKD to evaluate the effect of early invasive versus conservative treatment strategy on long-term outcome. They substantiated the observations of the TACTICS-TIMI 18 trial by demonstrating a reduction in the raised risk of the composite of death and MI in patients with creatinine clearance $<90$ $\mathrm{ml} / \mathrm{min}$. These findings were also in accordance with two other previous studies that tried to address this issue. Keeley et al. [23] examined the outcomes of CKD patients with ACS in a large and prospectively collected database. They pointed out that long-term survival of patients with an estimated GFR $<60 \mathrm{ml} / \mathrm{min} / 1.73 \mathrm{~m}^{2}$ was substantially superior in the patients treated with percutaneous coronary revascularization when compared with medical therapy alone. In another study, Hemmelgarn et al. [24] compared survival by treatment group (CABG, PCI or no revascularization) for patients with dialysis-dependent kidney disease, nondialysis-dependent kidney disease and a reference group. Overall, patients with kidney disease had poorer survival than the reference group, but revascularization was associated with a lower risk of death than no revascularization for all categories of kidney function.

A GUSTO-IV substudy showed lower 1-year mortality following revascularization in patients with renal dysfunction, with the absolute difference greater in patients with more severe renal impairment [25]. A recent collaborative meta-analysis of five randomized trials that enrolled approximately 1,500 patients with CKD illustrated that the benefits of an early invasive strategy were preserved in CKD patients with unstable angina or non-ST MI. This approach reduced the risk of rehospitalization, death and nonfatal reinfarction [8].

\section{Suggested Approach}

We suggest wider use of coronary angiogram/intervention in CKD patients with ACS. We believe that in the setting of evolving STEMI, recurrent angina with ST segment depressions/raised cardiac enzymes or ACS with signs of acute heart failure/cardiogenic shock, there is no degree of renal dysfunction that constitutes a contraindication to immediate coronary intervention. In these situations, a patient's life is at risk and an aggressive approach is required to reperfuse the ischemic myocardium. This practice will also give us the opportunity to study the effect of myocardial revascularization in patients with advanced CKD - a subgroup that has usually been excluded from clinical studies.

Prophylactic interventions should be instituted to reduce the risk of ICI-AKI prior to coronary angiography. These include intravascular volume expansion with iso- 
tonic saline or isotonic sodium bicarbonate, employing iso-osmolal or a nonionic low osmolality contrast medium (other than iohexol or ioxaglate) and limiting the dose of contrast medium to the minimum volume compatible with a diagnostic study.
We recognize that integration of an interventional approach into routine management of CKD stage IV and V patients may increase the risk of progression of renal disease and need for renal replacement therapy in a subset of these patients - a 'renal' price to pay for better cardiac outcomes, but worth the value.

\section{References}

1 Batter A: The Euro Heart Survey of Acute Coronary Syndromes (EHSACS). Eur Soc Cardiol Sci Sessions, Stockholm, September 2001.

$\checkmark 2$ Thom T, Haase N, Rosamond W, Howard VI, Rumsfeld J, Manolio T, Zheng ZJ, Flegal K, O’Donnell C, Kittner S, Lloyd-Jones D, Goff DC Jr, Hong Y, Adams R, Friday G, Furie K, Gorelick P, Kissela B, Marler J, Meigs J, Roger V, Sidney S, Sorlie P, Steinberger J, WasserthielSmoller S, Wilson M, Wolf P: Heart disease and stroke statistics - 2006 update: a report from the American Heart Association Statistics Committee and Stroke Statistics Subcommittee. Circulation 2006;113:e85-e151.

- 3 Canadian Cardiovascular Society, American Academy of Family Physicians, American College of Cardiology, American Heart Association, Antman EM, Hand M, Armstrong PW, Bates ER, Green LA, Halasyamani LK, Hochman JS, Krumholz HM, Lamas GA, Mullany CJ, Pearle DL, Sloan MA, Smith SC Jr, Anbe DT, Kushner FG, Ornato JP, Pearle DL, Sloan MA, Jacobs AK, Adams $\mathrm{CD}$, Anderson JL, Buller CE, Creager MA, Ettinger SM, Halperin JL, Hunt SA, Lytle BW, Nishimura R, Page RL, Riegel B, Tarkington LG, Yancy CW: 2007 focused update of the ACC/AHA 2004 guidelines for the management of patients with ST-elevation myocardial infarction: a report of the American College of Cardiology/American Heart Association Task Force on Practice Guidelines. J Am Coll Cardiol 2008;51:210-247.

-4 American College of Cardiology/American Heart Association Task Force on Practice Guidelines: ACC/AHA 2007 guidelines for the management of patients with unstable angina/non-ST-elevation myocardial infarction. J Am Coll Cardiol 2007;50:e1-e157.

5 Chertow GM, Normand SL, McNeil BJ: 'Renalism': inappropriately low rates of coronary angiography in elderly individuals with renal insufficiency. J Am Soc Nephrol 2004; 15:2462-2468.

-6 Keough-Ryan TM, Kiberd BA, Dipchand CS, Cox JL, Rose CL, Thompson KJ, Clase CM: Outcomes of acute coronary syndrome in a large Canadian cohort: impact of chronic renal insufficiency, cardiac interventions, and anemia. Am J Kidney Dis 2005;46:845-855.

7 Inrig JK, Patel UD, Briley LP, She L, Gillespie BS, Easton JD, Topol EJ, Szczech LA: Mortality, kidney disease and cardiac procedures following acute coronary syndrome. Nephrol Dial Transplant 2008;23:934-940.
8 Charytan DM, Wallentin L, Lagerqvist B, Space R, De Winter RJ, Stern NM, Braun Wald E, Cannon CP, Chowder NK: Early angiography in patients with chronic kidney disease: a collaborative systematic review. Clin J Am Soc Nephrol 2009;4:1032-1043.

-9 Asim M: Prevention of iodinated contrast induced acute kidney injury (ICI-AKI) - what have we learnt so far? Saudi J Kidney Dis Transpl 2009;20:753-765.

10 Newhouse JH, Kho D, Rao QA, Starren J: Frequency of serum creatinine changes in the absence of iodinated contrast material: implications for studies of contrast nephrotoxicity. AJR 2008;191:376-382.

11 Mehran R, Aymong ED, Nikolsky E, Lasic Z, Iakovou I, Fahy M, Mintz GS, Lansky AJ, Moses JW, Stone GW, Leon MB, Dangas G: A simple risk score for prediction of contrast induced nephropathy after percutaneous coronary intervention: development and initial validation. J Am Coll Cardiol 2004;44: 1393-1399.

12 Kumar N, Dahri L, Brown W, Duncan N, Singh S, Baker C, Malik I, Palmer A, Griffith M, Cairns T, Taube D: Effect of elective coronary angiography on glomerular filtration rate in patients with advanced chronic kidney disease. Clin J Am Soc Nephrol 2009;4: 1907-1913.

13 Reddan DN, Szczech LA, Tuttle RH, Shaw LK, Jones RH, Schwab SJ, Smith MS, Califf RM, Mark DB, Owen WF Jr: Chronic kidney disease, mortality, and treatment strategies among patients with clinically significant coronary artery disease. J Am Soc Nephrol 2003; 14:2373-2380.

- 14 Go AS, Chertow GM, Fan D, McCulloch CE, Hsu CY: Chronic kidney disease and the risks of death, cardiovascular events, and hospitalization. N Engl J Med 2004;351: 1296-1305.

15 Januzzi JL, Cannon CP, DiBattiste PM, Murphy S, Weintraub W, Braunwald E: Effects of renal insufficiency on early invasive management in patients with acute coronary syndromes (the TACTICS-TIMI 18 trial). Am J Cardiol 2002;90:1246-1249.

-16 Shlipak MG, Fried LF, Cushman M, Manolio TA, Peterson D, Stehman-Breen C, Bleyer A, Newman A, Siscovick D, Psaty B: Cardiovascular mortality risk in chronic kidney disease: comparison of traditional and novel risk factors. JAMA 2005;293:1737-1745.
17 Henry RM, Kostense PJ, Bos G, Dekker JM, Nijpels G, Heine RJ, Bouter LM, Stehouwer $\mathrm{CD}$ : Mild renal insufficiency is associated with increased cardiovascular mortality: the Hoorn Study. Kidney Int 2002;62:1402-1407.

-18 Santopinto JJ, Fox KA, Goldberg RJ, Budaj A, Piñero G, Avezum A, Gulba D, Esteban J, Gore JM, Johnson J, Gurfinkel EP: Creatinine clearance and adverse hospital outcomes in patients with acute coronary syndromes: findings from the Global Registry of Acute Coronary Events (GRACE). Heart 2003;89:1003-1008.

19 Johnston N, Jernberg T, Lagerqvist B, Wallentin L: Early invasive treatment benefits patients with renal dysfunction in unstable coronary artery disease. Am Heart J 2006; 152:1052-1058.

20 Al Suwaidi J, Reddan DN, Williams K, Pieper KS, Harrington RA, Califf RM, Granger CB, Ohman EM, Holmes DR Jr: Prognostic implications of abnormalities in renal function in patients with acute coronary syndromes. Circulation 2002;106:974980.

-21 Keith DS, Nichols GA, Gullion CM, Brown JB, Smith DH: Longitudinal follow-up and outcomes among a population with chronic kidney disease in a large managed care organization. Arch Intern Med 2004;164:659-663.

22 FRISC-2 Investigators: Invasive compared with non-invasive treatment in unstable coronary artery disease: FRISC II prospective randomized multicentre study. Lancet 1999; 354:708-715

23 Keeley EC, Kadoka R, Soman A, Borzoi S, McCullough PA: Analysis of long-term survival after revascularization in patients with chronic kidney disease presenting with acute coronary syndromes. Am J Cardiol 2003;92: 509-514.

-24 Hemmelgarn BR, Southern D, Colleton BF, Mitchell LB, Knutson ML, Ghazi WA: Survival after coronary revascularization among patients with kidney disease. Circulation 2004;110:1890-1895.

25 James SK, Lind Back J, Tally J, Siegbahn A, Avenge P, Armstrong P, Cliff R, Simons ML, Wallentin L, Lindahl B: Trooping-T and Nterminal pro-B-type natriuretic peptide predict mortality benefit from coronary revascularization in acute coronary syndromes: a GUSTO-IV substudy. J Am Coll Cardiol 2006;48:1146-1154. 


\section{Editorial Comment}

M. El Nahas, Sheffield

The minireview by Asim and Jeffrey argues for more aggressive imaging and interventions in symptomatic patients with CKD and coronary artery disease (CAD). They make the valid point that coronary imaging with iodinated contrast media is warranted in these high-risk patients with considerably increased morbidity and mortality. They also discuss evidence that interventions, i.e. percutaneous coronary intervention or bypass surgery (CABG), improve outcomes. It is clear that in such patients the risk:benefit of imaging and interventions favors action. More controversial would be investigations in asymptomatic CKD5 patients who are also at high risk of CAD. In these patients, stress myocardial perfusion imaging (MPI) would be the preferred initial investigation as it is a sensitive and well-established means of predicting cardiovascular events that is not associated with risk of nephrotoxicity.

In addition to the approaches to manage CKD patients with symptomatic CAD highlighted in this minireview, nephrologists need to consider the overall quality of care they provide CKD patients with CAD. Studies show that
CKD patients with CAD have suboptimal care and risk modification compared to others. In one large report from the United States, control of blood pressure and/or diabetes, management of dyslipidemia, and cessation of smoking were all suboptimally managed in CKD patients. Those at higher risk of mismanagement of CAD risk factors were older CKD patients, males, those with high BMI and, interestingly, those under care of a nephrologist [1]. Overall, the review by Asim and Jeffrey encourage nephrologists to be more aggressive with investigations and management of CKD patients with symptomatic CAD, but nephrologists also need to be more aggressive in their approach to prevention, risk management and early treatment of CKD patients at risk of CAD.

\section{Reference}

McCullough PA, et al: Cardiovascular risk modification in participants with coronary disease screened by the Kidney Early Evaluation Program. Intern Med J 2010;40:833-841. 